\title{
A CASA DA CÂMARA DE SÃO LUÍS E O MOVIMENTO HIGIENISTA: A SEGREGAÇÃO DA CADEIA NO SÉCULO XIX
}

\author{
THE COUNCIL'S HOUSE OF SÃO LUÍS AND THE HYGIENIST \\ MOVEMENT: THE JAIL SEGREGATION IN THE XIX CENTURY
}

Antonia da Silva Mota ${ }^{1}$

\begin{abstract}
RESUMO
A Casa de Câmara e Cadeia de São Luís (MA) e as mudanças pelas quais passou sob as injunções do movimento "Higienista" são o foco deste estudo. O embate entre o discurso sanitarista dos médicos, que mais e mais se afirmava, com a mentalidade atrasada das elites locais alcançou um novo patamar na segunda metade do século XIX, quando então a cadeia pública e os encarcerados foram colocados fora dos muros da cidade, muito distante de seu sítio original, na praça principal e ao lado do palácio de governo. No final dos oitocentos, a secular edificação passou a abrigar a Intendência Municipal, passando por um processo de aformoseamento, adquirindo contornos neoclássicos.
\end{abstract}

PALAVRAS-CHAVE: Casa de Câmara e Cadeia; Higienismo; São Luís: Maranhão.

\begin{abstract}
The House of Council and Jail of São Luís (MA) and the changes it went through under the injunctions of the "Hygienist" movement are the focus of this study. The conflit resulting from the medical discourse, which more and more asserted itself, with the old-fashioned mentality of the elites who held power in the city only advanced in the second half of the nineteenth century, when then the public jail and the incarcerated were placed outside the city walls, far from the main square and beside the government palace. At the end of the 1800s, the secular building started to house the Municipal Intendance, undergoing a process of embellishment, acquiring neoclassical contours.
\end{abstract}

KEYWORDS: The House of Council and Jail; Hygienism; São Luís; Maranhão.

\section{INTRODUÇÃOO}

No ano de 2019, foram comemorados os quatrocentos anos de instituição da Casa de Câmara e Cadeia em São Luís do Maranhão. Um dos eventos organizado reuniu historiadores das Universidades Federais e Estaduais, dos Institutos Federais de

1 Docente do Programa de Pós-Graduação em Gestão da Educação Básica - PPGGEB e do Mestrado Profissional em Ensino de História - ProfHistória, da Universidade Federal do Maranhão. E-mail: as.mota@ufma.br. 
Educação, museólogos do Arquivo Público, da Biblioteca Benedito Leite e um pesquisador visitante da Universidade Nova de Lisboa, Portugal. Contou também com uma seleta assistência, composta por alunos de graduação e de pós-graduação. As palestras versaram sobre os mais diversos temas, sendo que em minha contribuição focalizei a Casa de Câmara e Cadeia, o antigo prédio do Conselho Municipal, localizado no mesmo sítio desde sua fundação, em 1619, até meados do século XX. Na pesquisa bibliográfica sobre a imponente construção, logo percebemos que havia ocorrido uma mudança significativa quando a Cadeia foi apartada do prédio da Câmara, em 1856. Fato que nos causou grande estranhamento, pois a Cadeia pública havia permanecido ao lado do Palácio de Governo, na praça principal da cidade, por quase três séculos!

A Casa de Câmara e Cadeia de São Luís foi instituída nos tempos do Antigo Regime, em que, para manter a ordem, as autoridades metropolitanas precisavam da visibilidade dos instrumentos de tortura (pelourinho) e da possibilidade iminente da privação da liberdade, representada pela cadeia. Em 1856, quando a sociedade já havia alcançado um novo patamar com a disseminação das ideias iluministas, notadamente com a propagação das medidas sanitárias, a Cadeia pública foi levada para outro sítio, afastada do perímetro urbano.

Através da revisão do que já se conhece sobre esse importante prédio público, ficou claro que, após a segregação da Cadeia, logo foram realizadas reformas que culminaram no aformoseamento do antigo prédio colonial, que ganhou traços neoclássicos, passando a abrigar a Intendência Municipal, já no final do século XIX.

\section{A LINHA DE PESQUISA CULTURA MATERIAL E HISTÓRIA}

Embora não seja uma novidade a utilização de vestígios materiais como evidência histórica, nas últimas décadas a linha de pesquisa que se utiliza da Cultura Material para compreender mudanças sociais se consolidou. Sabemos que Heródoto, no século V a. C., já descrevia as pirâmides para expressar a grandiosidade da cultura que floresceu no vale do rio Nilo, sendo seguido a partir de então pela maioria dos historiadores, que se utiliza de artefatos, ruínas, construções, como uma fonte para o conhecimento do passado. No entanto, acreditamos que os balizamentos metodológicos somente se firmaram na segunda geração do Movimento dos Annales e que basicamente consistem em relacionar mudanças na cultura material a processos históricos. 
A busca por renovação das fontes, objetos e abordagens direcionaram os estudos de Fernand Braudel, que, em sua obra Civilização Material e Capitalismo, afirmou a importância do estudo das transformações nas formas de moradia, de alimentação, do mobiliário, dos utensílios, das vestimentas para compensar a exiguidade das fontes escritas (1995). Seu estudo inspirador sobre o espaço do Mediterrâneo frutificou em inúmeros estudos mais localizados, como os do historiador francês Daniel Roche, que escreveu a História das Coisas Banais: o nascimento do consumo nas sociedades do século XVII ao XIX (2000). O direcionamento teórico-metodológico foi seguido, pois a partir da evidência da multiplicação dos objetos o estudioso chegou a um fenômeno novo: o consumo.

Os estudos em Cultura Material entrelaçam domínios diversos, possibilitando a interdisciplinaridade. Conhecimentos advindos da arquitetura e da arqueologia dão substância aos estudos históricos e vice-versa. Significam novas formas de abordagem, como o viés da História do Cotidiano, da Vida Privada etc. No Brasil, por exemplo, pesquisas na área da arqueologia contribuíram significativamente para o conhecimento da vida material no Quilombo de Palmares. O historiador/arqueólogo Pedro Funari nos desvelou nuances inimagináveis para esse objeto, antes conhecido somente pela visão dos que reprimiram o ajuntamento insurgente. A constatação de que os habitantes de Palmares interagiam com as comunidades de seu entorno através das mercadorias trocadas, ou o fato da presença de indígenas convivendo com os aquilombados de origem africana seriam inimagináveis se não fossem os estudos arqueológicos realizados pela equipe de Funari da Unicamp/SP.

Hodiernamente, se multiplicam os estudos que têm como metodologia a análise da cultura material, sendo o mais destacado, pela abundância de recursos iniciais e pela excelência de seus resultados, as pesquisas sobre o Cais do Valongo, no Rio de Janeiro. Uma equipe de arqueólogos e historiadores, com recursos disponibilizados por ocasião das Olimpíadas, conseguiu a proeza de escavar o antigo Cais, submerso por camadas de aterro, que se tornou um marco para as pesquisas sobre o tráfico de africanos escravizados para o continente americano.

\section{AS FONTES E A METODOLOGIA}


Para o estudo pretendido sobre a mudança ocorrida na Casa de Câmara e Cadeia com as medidas sanitárias do século XIX, utilizaremos três fontes em especial: os Álbuns da Tipogravura Teixeira (1899 e 1908), o Primeiro Caderno de Recenseamento da Capital, feito em 1855 e a Planta da cidade de São Luís, feita por J. Veiga, em 1858. As imagens do prédio do final do século XIX foram fundamentais em nosso estudo, pela visibilidade da edificação. Por outro lado, constatamos que na contagem populacional de 1855, a Cadeia ainda estava no térreo da sala do Conselho Municipal, como atesta a listagem dos oitenta presos - composta por seus nomes, naturalidade, idade, condição civil e jurídica etc. Utilizaremos o método demográfico para realizar uma análise desse contingente, verificando sua idade média, seu perfil por sexo, cor, condição jurídica etc. O objetivo é, com os dados disponíveis, produzir um "retrato" dos encarcerados, o que nos possibilitará uma compreensão mais ampla sobre os motivos de sua segregação.

Na planta da cidade, feita por J. Veiga, três anos depois, os encarcerados já não estavam mais ali, como demonstram as legendas e a representação das construções, tanto da Câmara, quanto da nova Casa de Correição, posta do outro lado da cidade, muito afastada do lugar onde esteve por dois séculos e meio. Na referida Planta foi representado tanto o prédio em formato de "U", na praça do palácio, quanto o Pelourinho que foi deslocado para quadras distante de seu espaço original, saindo de frente da Câmara - como era de costume no Império português, sendo fincado no Largo do Carmo, um espaço subalterno na configuração daquela urbe.

Outra fonte que nos permite visualizar as transformações mencionadas são as imagens feitas sobre a antiga Casa de Câmara e Cadeia. Escolhemos aquelas constantes no Álbum de Gaudêncio Cunha, de 1908. Poderíamos ter usado uma fotografia de quase dez anos antes, a da Alfaiataria Teixeira (1899); no entanto, o ângulo escolhido (frontal) e a presença de muitas pessoas à frente, fez com que nossa escolha recaísse sobre a do Álbum, feito em 1908.

As informações trazidas pelos historiadores regionais, cotejadas com a observação minuciosa dos documentos elencados acima e a análise demográfica do perfil dos presos nos permitiu dar nossa contribuição sobre a história do Monumento. Buscávamos algo que acusasse modificações na estrutura material como consequência de mudanças históricas; então, o recorte foi feito quando detectamos que a Cadeia foi apartada, na 
segunda metade dos oitocentos, como resultado das medidas sanitárias do grupo higienista.

\section{AS MUDANÇAS NA CONSTRUÇÃO ORIGINAL}

A Construção ainda está de pé, no mesmo local onde foi erigida uma casinha de pau a pique, em 1619, para abrigar o Conselho Municipal da cidade planejada. Claro que, ao longo de quatro séculos passou por várias intervenções em sua estrutura. O historiador César Marques informou que a Construção tal qual a conhecemos hoje só se deu no final do século XVII, em 1689, a partir de um registro que dizia:

Oficiando o sargento-mor Antônio de Barros Pereira, em 8 de março de 1689, disse: "a nossa obra da casa da Câmara temos tenção de que saia de pedra até o sobrado e por isso se trata de tirar alguma pedra que falta, e do sobrado pra cima será de taipa, e como Vmc. está em véspera de acabar a igreja, muita mercê nos faria se nos remetesse essas taipas, que ficam da obra para podermos aproveitar delas e de seus aparelhos" (1970, p. 169).

Os camaristas deixaram escapar de que forma eram feitos os alicerces e as paredes que davam sustentação ao sobrado. Eles faziam fôrmas de madeira e as preenchiam com pedras e argamassa, que levavam cal e óleo de baleia. São grossas paredes, que sustentavam o andar superior e o telhado, estes estruturados em madeira. $\mathrm{O}$ arquiteto do Instituto do Patrimônio Histórico Nacional, Olavo Silva Filho, observou que a técnica construtiva era a "taipa-de-pilão", predominante nos prédios públicos e igrejas mais antigas, pois, segundo este, a região oferecia "sambaquis para fabricação da cal e abundante jazidas de arenito ferruginoso, usado na estruturação das paredes mestras monolíticas e notavelmente sólidas, com espessuras variando em torno de $50 \mathrm{~cm}$ a 1,30 m" (1998, p. 99).

Em formato de "U", tradicionalmente eram assim estruturados os prédios dos Conselhos Municipais no Império português, pois esse formato permitia um máximo de privacidade do interior e a garantia de iluminação e frescor aos cômodos. Afirma Silva Filho que na arquitetura colonial portuguesa havia pouca distinção entre a forma de construção para fins de moradia e aquelas levantadas para abrigar prédios públicos: "não fossem as grades de segurança, passariam por residências, tamanha a aproximação tipológica entre elas" (1998, p. 119). 


\section{O AVANÇO DO MOVIMENTO HIGIENISTA NO SÉCULO XIX}

O cultivo e a exportação do algodão propiciaram o enriquecimento de algumas famílias no Maranhão, possibilitando que seus filhos pudessem estudar nos grandes centros europeus, trazendo as concepções higienistas para São Luís. Este movimento, que provocou mudanças nas cidades europeias e das Américas, já foi muito estudado pela historiografia. Seus feitos demonstram uma confluência de muitos fatores, mas principalmente se constitui no avanço do pensamento científico a partir do século XVIII. Os aglomerados urbanos, nas metrópoles e colônias, que sofriam com as sucessivas epidemias, tiveram que se render à mudança de hábitos conclamada pelos médicos. Estes convenceram as autoridades municipais sobre o perigo dos "miasmas" que, por exemplo, emanavam dos corpos em putrefação dentro das igrejas. Cumpre observar que não foram poucos os movimentos de resistência, mas a autoridade do discurso médico acabou por produzir uma mudança de mentalidade e novo ordenamento às cidades.

Um dos trabalhos mais interessantes no Brasil a retratar esse embate foi escrito pelo historiador baiano João José Reis. Segundo este, "a higienização das cidades passaria a fazer parte do dia a dia das Câmaras" (1991, p. 276). O autor relata a resistência que houve dos moradores de Salvador, Bahia, à pressão das autoridades para construção dos cemitérios fora dos muros da cidade. Tais propostas higienistas foram trazidas por jovens médicos formados na Europa que alertavam sobre os perigos à saúde pública com o costume de enterramento dos corpos nas igrejas. Ao final, os moradores tiveram que se submeter aos novos tempos, em grande parte devido às sucessivas epidemias que ceifavam milhares de vidas.

Sobre as condições sanitárias na província do Maranhão, no século XIX, existem vários estudos. Um dos mais bem embasados é o de Agostinho Coe, que tratou justamente do "higienismo" em terras maranhenses. Segundo o autor, assim como em Salvador, o movimento foi trazido por jovens da elite formados em medicina nas universidades da França e de Portugal. O estudo focaliza a mudança na forma de enterramento dos mortos em São Luís, que após muitos avanços e recuos, os médicos sanitaristas conseguiram que deixassem o recinto das igrejas e o pequeno cemitério da Misericórdia. Naquele momento, os enterros passaram a ser feitos no Cemitério do Gavião, um amplo espaço, longe da cidade e das fontes de água, deixando de contaminá-las com os "miasmas dos corpos em putrefação". 
Apesar da maior visibilidade do discurso médico, Agostinho Coe mostra em sua pesquisa que o movimento higienista teve que ultrapassar muitas barreiras, a começar pela igreja católica, em especial, as irmandades religiosas, que sobreviviam em grande parte dos rendimentos oriundos dos rituais fúnebres. Coe mostrou que a inauguração do novo Cemitério em São Luís se arrastou por décadas, somente se realizando após uma grande epidemia de varíola (1855) que resultou em milhares de mortos. O autor ressalta que em grande parte, o movimento higienista se beneficiou das iniciativas de um profissional dedicado, e citando o historiador César Marques, afirma que o alcantarense José da Silva Maia muito jovem foi enviado por sua família à França, onde fez os estudos secundários e alcançou o grau de medicina em 1844. O jovem médico retornou ao Maranhão, mais precisamente a São Luís, onde exerceu seu ofício, assim como ocupou importantes cargos públicos na Câmara e na Assembleia Provincial. Segundo Coe, impressionado com a situação sanitária da província, iniciou a propaganda higienista fundando o Jornal da Philomática Maranhense, sendo autor do Manifesto onde, entre outras coisas relevantes, apontou horrorizado:

No que diz respeito à Cadeia da cidade, Silva Maia afirmava existirem apenas dois quartos imundos, situados na principal praça da cidade, onde eram presos indistintamente o branco com o negro escravo, o incorrigível com o acusado inocente. Além disso, "é dentro destes mesmos quartos que os prezos na presença uns dos outros, fazem todas as suas funcções naturaes, infestando assim o ar que respirão" (Grifos do autor do Manifesto. Coe, 2008, p.49).

O conteúdo da citação manifesta a indignação do jovem médico com as condições sanitárias do ambiente visitado, assim como a mentalidade escravista da época, pois logo lhe chamou atenção que não havia acomodações separadas para "livres" e escravizados. Ao longo de seu estudo, Agostinho Coe detalha as dificuldades encontradas por esses jovens médicos ao apresentarem ideias tão inovadoras. Segundo este, havia uma sistemática na forma de atuação dos profissionais, que apontavam para necessidade da realização de uma organização mais racional do espaço, como detalhou o médico Silva Maia em seu Manifesto:

$\mathrm{Na}$ ordem de prioridades estava o estudo de instituições e estabelecimentos públicos, buscando conhecer seus defeitos, vícios e abusos e indicando os meios de corrigi-los. As primazias seriam o exame sanitário dos hospitais, colégios, escolas públicas, mercados, açougues, currais, matadouros, teatros, quartéis, prisões e cemitérios" (Apud COE, 2008, p. 50). 
Figura 1. Praça do Palácio na Planta da cidade de São Luís, por J. Veiga, de 1858.

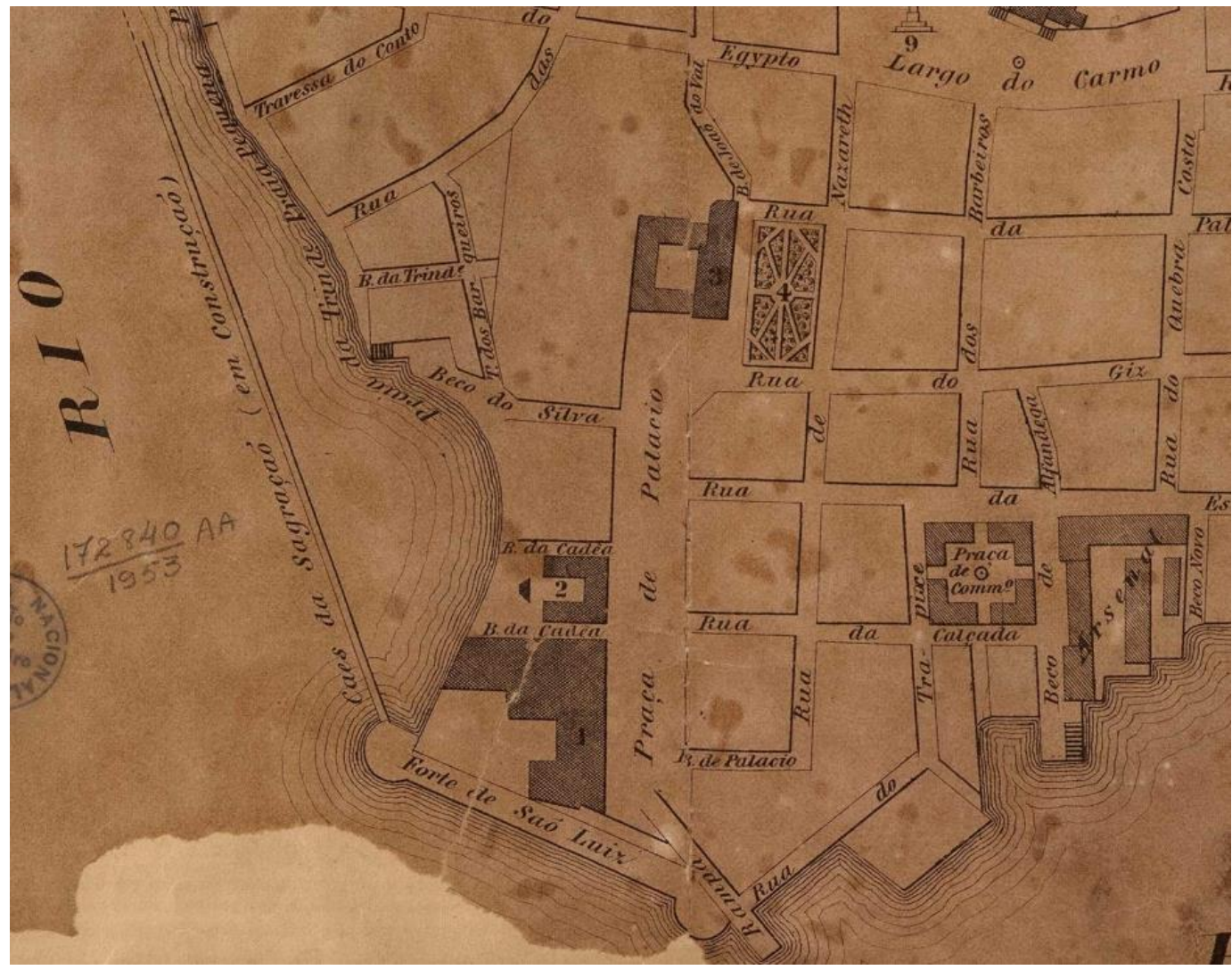

Fonte: Biblioteca Digital Luso-brasileira e Biblioteca Nacional Digital do Brasil. Disponível no site http://bdlb.bn.gov.br/acervo/handle/123456789/272638?locale-attribute=pt PT

Na intenção de compreender a oposição dos médicos sanitaristas à localização da prisão, realizamos um estudo do perfil dos encarcerados, pois eles foram contados quando do Recenseamento feito na Capital, em 1855. Os dados desses indivíduos são expostos no item que segue.

\section{OS ENCARCERADOS, SEU PERFIL DEMOGRÁFICO}

Em 1855, foi iniciada a contagem da população de São Luís, quando se constatou que, ao lado do Palácio de governo estava a "Casa da Câmara Municipal, Tribunal do Jury e Cadêa". Inicialmente, aparece a relação próxima entre os dois prédios públicos, pois nenhum morador foi recenseado na última Casa, excetuando-se os presos. Então supomos que a guarda dos mesmos fosse feita pelos homens que moravam ao lado, no Palácio do Ex. ${ }^{\text {mo }}$ Snr ${ }^{\text {or }}$ Presid. ${ }^{\text {te }}$ da Província. Na relação dos moradores do "Forte de São Luís", como foi denominado o logradouro no Recenseamento, além do capitão, do furriel, de suas famílias e escravos, aparecem dezessete homens livres, todos dados como 
"pardos", de diferentes naturalidades. Existe grande possibilidade de esses homens serem aqueles que zelavam pelo cárcere.

Do outro lado do Beco, na Cadeia que ficava no andar térreo do Conselho Municipal, homens e mulheres foram arrolados na seguinte ordem: 21 "presos em custódia", 14 "indiciados", 40 "sentenciados" e seis "pronunciados". Obviamente que nessa listagem, os homens eram maioria; perfaziam 65 indivíduos. As mulheres, o restante (16), num total de 81 encarcerados. A média de idade era de 38 anos, alta para os padrões da época, em que as pessoas não viviam muito devido às condições de vida e as epidemias que grassavam de tempos em tempos. Os mais jovens dentre eles eram rapazes, na faixa dos 15 aos 17 anos, naturais de Caxias, Brejo e Tutóia, localidades muito distantes da Capital. Os mais velhos estavam na faixa dos 70 a 78 anos, representados por duas mulheres (Ana Rabelo e Maria Rodrigues, de Oeiras e Sobral, respectivamente); e um homem, José Ferreira de Sá, também de Sobral. A maior parte dos presos, grupo que somava setenta pessoas, estava na faixa etária dos 20 a 50 anos, portanto, na fase adulta e mais produtiva da vida.

Quanto à condição social dessa população, verificamos que os "livres" se sobressaíam, eram 63; os escravizados, 17, e apenas uma era "liberta". Sabemos que dificilmente se deixava um escravo preso, pois os donos logo se mobilizavam para libertálo e continuar a usufruir de sua força de trabalho. A não ser que tivesse cometido um crime muito grave ou fosse muito velho. De fato, constatamos que a média de idade dos escravizados recolhidos no cárcere era de quarenta anos (precisamente 40,7), e entre os do sexo masculino era bem mais alta, de 44 anos, pois o trabalho dos homens, em especial, era mais valorizado, diminuindo a probabilidade de serem deixados na prisão por muito tempo. Digno de nota é que, entre estes encontramos três africanos - Antônio, Faustino e Athanazio, obviamente que com idade avançada, entre 50 e 60 anos, todos solteiros. Todos os escravizados encarcerados estavam nessa mesma condição: eram solteiros.

Os dados como "pardos" eram a maioria dos encarcerados, reafirmando o que diz a historiografia, sobre a condição anômala dessa camada social dentro do sistema escravista. Quase sempre sem terra e sem ofício, a muitos destes indivíduos só restava a marginalidade, donde muitos se tornavam "agregados" e alguns acabavam presos. A diferença é que possuíam nome e sobrenome, como Quintiliano Rodrigues, de 17 anos, vindo da distante Tutóia. Quanto ao estado civil, embora a maioria fosse solteira, havia 
casados (11) e viúvos (06) entre eles. Neste último caso se encontrava Gualdina Maria Pereira, mulher de 40 anos, casada, supostamente da cidade de São Luís, pois foi assinalado "Maranhão" no item "naturalidade" referente à sua pessoa.

Quanto às localidades apontadas como de origem dos presos, aparecem lugares bem distantes, como África (4), Guiné (1), Piauhy (6), Pará (3), Pernambuco (2), Minas (1) Ceará (2), Sobral (5) e Oeiras (1). No entanto, a imensa maioria havia nascido na província e nas áreas fronteiriças. Supomos que todos os indicados como naturais do "Maranhão" fossem de São Luís, pois inúmeros outros encarcerados foram indicados como sendo de Brejo, de Pastos Bons, do Iguará etc., que também faziam parte do território maranhense. Nos registros de época, São Luís era nominada também como "Ilha do Maranhão", donde concluímos que os trinta presos que trazem essa indicação eram oriundos da Capital. A seguir, vieram localidades menores, daqui e de outras províncias, como Alcântara (3), Vila do Paço (2), Brejo (6), Caxias (3) e Pastos Bons (3). Os sítios seguintes tiveram apenas uma menção: Bacanga, Icatu, Cururupu, Munim, Iguará, Mearim e Tutóia. Sentimos falta de referência a indivíduos do Itapecuru, uma das regiões mais populosas da província. Será porque estão dentro daqueles nominados "Maranhão", ou porque naquela vila havia uma cadeia muito importante desde a Balaiada, ocorrida quinze anos antes? Difícil saber.

\section{A CADEIA SEGREGADA, O NOVO ESPAÇO DO PRESÍDIO}

Retomando o embate iniciado pelos médicos higienistas, Agostinho Coe aponta que a resistência às modificações na organização do espaço urbano vinha tanto dos moradores (arraigados a seus costumes seculares) quanto das autoridades municipais, apegadas a outras prioridades que não a saúde pública. Mas, a propaganda higienista logrou algum êxito, ainda que em grande parte devido às sucessivas epidemias e aos incômodos decorrentes do crescimento da cidade no século XIX.

Condenada sua localização pelos médicos higienistas desde meados dos oitocentos, após longa campanha de conscientização e ações nos órgãos públicos responsáveis, foi projetado um novo presídio. A escolha do terreno recaiu sobre um sítio localizado nas extremidades do perímetro urbano, por detrás da igreja dos Remédios, na área do "Genipapeiro", onde ficavam "os ranchos dos pretos da fazenda de Manuel José 
de Medeiros, senhor da Quinta do Marajá, ocupando os terrenos atrás da igreja até à beiramar, por todos os lados" (MARQUES, 1970, p 163).

Nessa mesma época, outras modificações no sentido do "sanitarismo" estavam ocorrendo, o que também contribuiu para o avanço da causa. César Marques assinala que, “em 1856, iniciava-se a instalação pela Companhia Anil, de "Chafarizes públicos com água canalizada do rio Anil" (Apud SILVA F. p. 83). Germano, Ribeiro e Lopes, analisando o discurso dos presidentes de província da época, depreenderam que estava em curso um "projeto modernizador", de "embelezamento de São Luís, ainda que as autoridades privilegiassem as instalações portuárias, descuidando das necessidades da maioria da população". Os autores perceberam que nesse projeto havia um objetivo, modernizar as áreas portuárias, favorecendo as atividades comerciais, cujo modelo estava nas grandes cidades europeias e na capital do império brasileiro:

Durante o período imperial, particularmente durante o segundo reinado, as obras públicas ganham destaque nos relatórios dos presidentes da Província do Maranhão, informando datas, custos e avanços da instalação de iluminação pública a gás encanado, calçamento de inúmeras ruas, reformas no palácio do governo e na Capitania do Porto, construção do dique na praia das Mercês, escavação do mar na baía de São Marcos e no porto e a construção de um paredão na Praia Pequena, obras que apontam para uma mudança fulcral no espaço urbano de São Luís naquele período, cuja "architectura moderna" pretendida inseriria a cidade no mesmo padrão de modernização de outras grandes e importantes cidades do mundo, mas especialmente a capital do Império, o Rio de Janeiro (2011, p. 05).

Nesse movimento de "modernização", não havia mais função para uma Cadeia posta na praça central da cidade. Mesmo assim, ao longo de vinte e cinco anos, obras começavam e não terminavam no local escolhido. Até que, em 1855, graças ao impulso dado pelo presidente de província José Joaquim Teixeira Vieira Belfort, que agiu para que se "procedesse aos consertos necessários em um dos raios do edifício, na casa da administração e muralhas interiores, em ordem a fazer-se para ali a transferência dos presos, que existiam na cadeia, então nas grandes lojas do paço da Câmara Municipal" (Marques, 1970, p. 163).

O prédio construído na área do "Genipapeiro" era térreo, formado por quatro alas compridas, onde deveriam ficar os presos, uma construção circular ao meio e uma parte retangular na fronteira do prédio, onde ficava a administração. À frente, existia uma grande praça, pois havia muito espaço a ser ocupado nesse lugar ermo. Se compararmos na planta da cidade já mencionada, a nova edificação era três vezes maior que a Casa do 
Conselho, onde originalmente estava a cadeia. A transferência para o novo prédio aconteceu a 13 de fevereiro de 1856 (Álbum de 1899, p. 75).

Figura 2. Praça de Correição. Planta da cidade de São Luís, por J. Veiga, de 1858.

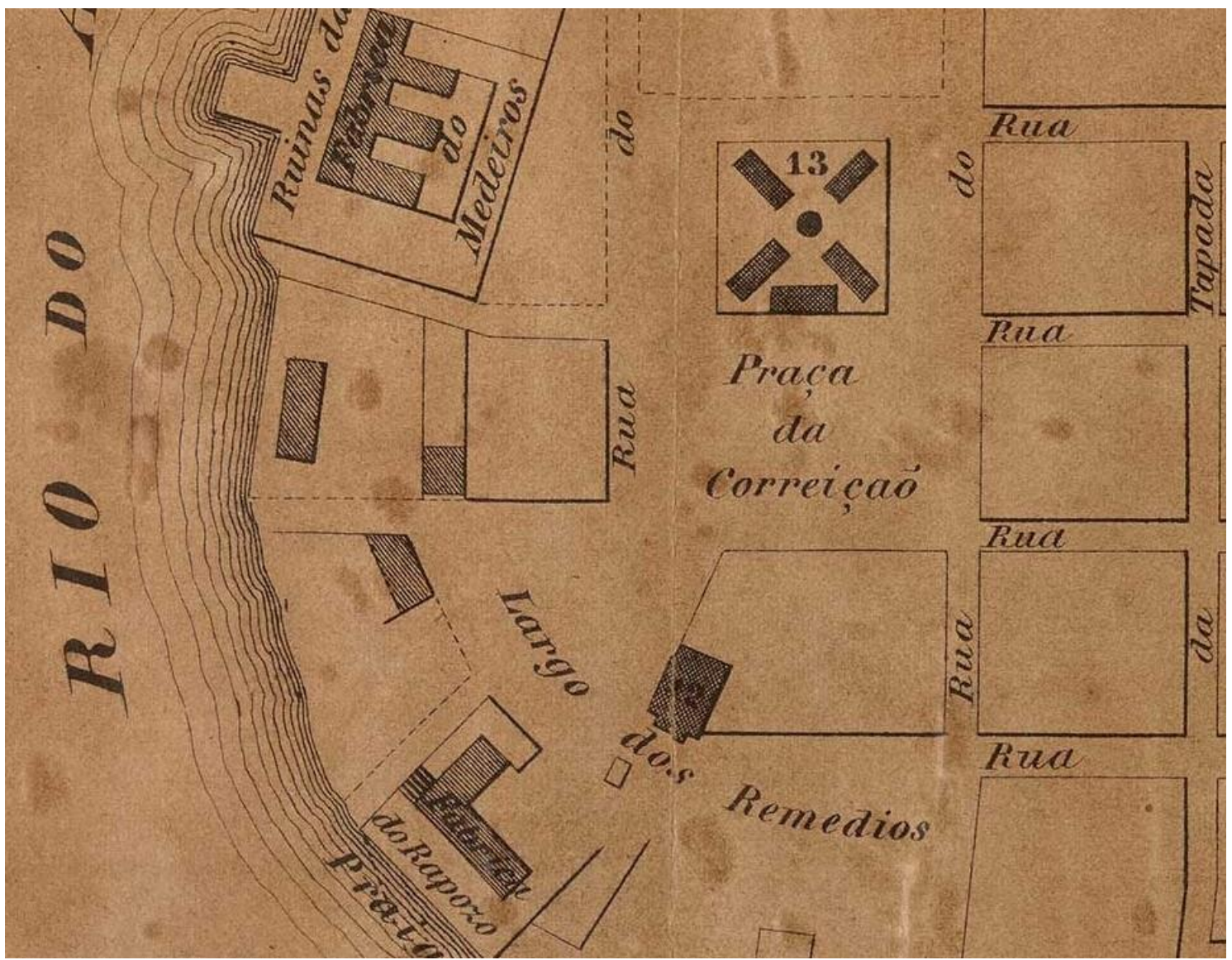

Fonte: Biblioteca Digital Luso-brasileira e Biblioteca Nacional Digital do Brasil. Disponível no site http://bdlb.bn.gov.br/acervo/handle/123456789/272638?locale-attribute=pt PT

\section{AS REFORMAS SE INTENSIFICARAM QUANDO O PRÉDIO PASSOU A ABRIGAR A INTENDÊNCIA MUNICIPAL}

Após a segregação dos presos no novo presídio, abriu-se a possibilidade de intervenções na construção secular do Largo do Palácio, o que passou a ocorrer com frequência. Segundo nos reporta o Álbum da Alfaiataria Teixeira, que reproduziu um texto de José Ribeiro do Amaral, em 1885, o prédio foi restaurado e melhorado sob a orientação do mestre carapina Basílio Antônio Sodré. Informou ainda Ribeiro do Amaral que, em 1889, novos melhoramentos foram feitos, em especial, a edificação de uma elegante escadaria, preservada até hoje. Agilizadas com recursos da "Intendência 
Municipal" e na gestão do coronel Alexandre Collares Moreira Junior, as obras consistiam em qualificações estruturais:

A reforma exterior do edifício, quer a da frente, quer as das faces laterais, com ornamentação; as balaustradas da platibanda e as de apoio das janelas; o preparo de quatro salões do lado direito, que estavam abandonados e foram assoalhados, estucados e forrados; os consertos do assoalho e dos forros do andar superior; a substituição de todas as janelas da frente e das faces laterais; a substituição de ripas e telhas e, finalmente, a pintura geral e ornamentação interna (Álbum 1899, p. 75).

Ribeiro do Amaral detalhou no texto que novas técnicas construtivas foram empregadas para reforçar "as paredes da frente e de uma das laterais, que ameaçavam ruína, por alvenaria de tijolo”. Também foram feitas outras alterações, como:

A substituição das calhas, que em alguns pontos estavam reduzidas a uma peneira, por uma outra de alvenaria revestida de cimento, sobreposta ainda por uma de cobre; a canalização do esgoto das latrinas para o mar e a colocação de novos aparelhos; as janelas do pavimento térreo, do lado agora preparado de novo e que dão para o mar sofreram modificações, sendo rasgadas umas, abertas outras, recebendo grades de ferro, rótulas e vidraças (Álbum 1899, p. 75)

O texto assinala que, nessa época, 1899, no andar superior funcionava o salão de reuniões da Câmara e no inferior, a "repartição da Intendência com todas as suas dependências" (Álbum 1899, p. 76). Na publicação, uma fotografia foi colocada antes do texto que enumerou as benfeitorias realizadas, a imagem foi legendada como “Intendência Municipal”. Os autores do Álbum não se deram conta da inversão evidente. Ainda que historicamente aquele espaço ainda estivesse ligado ao Conselho Municipal, com toda a importância que essa instituição teve para cidade em seus trezentos anos de existência, as reformas feitas apontavam para ocupação definitiva do prédio pela Intendência Municipal, o poder executivo. Não demorou muito tempo, e a Câmara, instituição que idealmente representava "a Res Publica", também foi segregada para espaços subalternos da urbs.

Figura 3: Antiga Casa de Câmara e Cadeia, em 1908. 


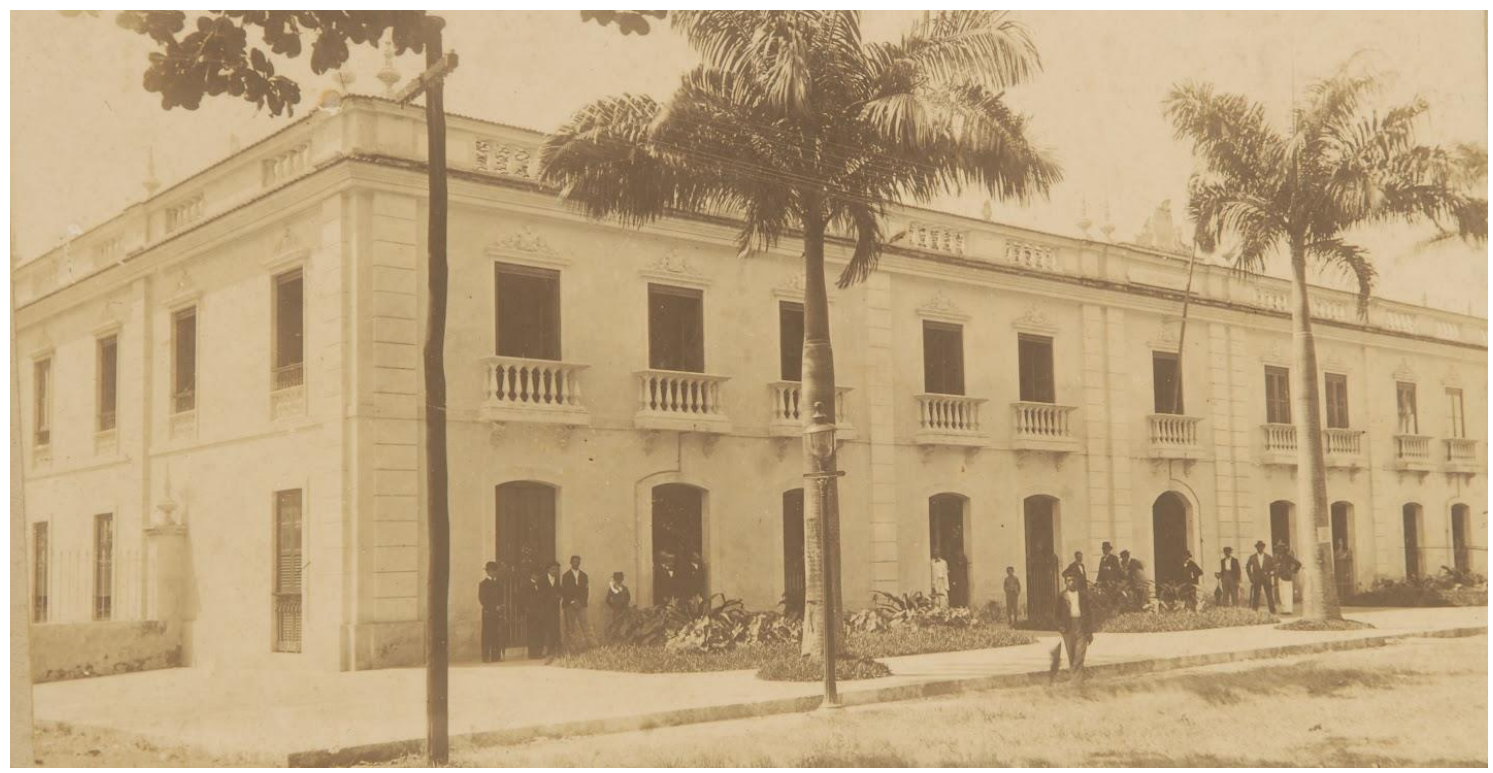

Fonte: Álbum de Gaudêncio Cunha, 1908. Domínio público.

\section{A VISITA AO MONUMENTO}

Parte obrigatória da metodologia das pesquisas em Cultura Material consiste na observação in loco do Monumento. Nossa intenção era encontrar algum resquício da antiga Cadeia na hoje sede da Prefeitura Municipal. Infelizmente, o prédio estava em reformas, então pudemos apenas contemplar a fachada e bisbilhotar seus fundos. Constatamos que de forma geral o edifício se manteve preservado, pois faz parte do Centro Histórico, Patrimônio da Humanidade tombado pela UNESCO. Apenas houve o acréscimo em sua entrada do busto de um "nobre francês", uma vez que a hoje querem que seja chamado de "Palácio de La Ravardière". Uma tentativa vã de ligar a Fundação da cidade aos franceses, que estiveram por estas terras por apenas três anos, deixando-a em 1615; portanto, quatro anos antes da primeira edificação de pau a pique do Conselho Municipal. Do ponto de vista histórico, não há como ligar esse Monumento aos franceses; tal pretensão foi largamente estudada pela historiadora Maria de Lourdes Lacroix (2002).

Continuando a visita, pela fresta da porta principal, vi a escada imponente, em madeira nobre, perfeitamente preservada. Invadindo sem autorização os fundos, fotografando com o celular, identifiquei claramente o prédio original e a expansão feita depois, que desfez o formato original em "U", como atestam as novas janelas e o beiral do telhado. Com certeza não encontraram mais os artífices e o material para manter a linha arquitetônica, ou não se interessaram por fazê-lo. 
Nos fundos que antes davam para maré (como sabemos por descrições e imagens feitas no final dos oitocentos), hoje existem um estacionamento, depois um muro e por trás deste, rua completa de casas e uma grande avenida à beira-mar. Sucessivos aterramentos e a construção do Cais da Sagração afastaram o canal antes navegável por grandes embarcações, modificando sobremaneira o espaço onde foram fincados os pilares da construção seiscentista. Mesmo assim, avaliamos que o espaço ainda preserva a memória dos tempos em que a Casa de Câmara e Cadeia era o terceiro edifício em importância no Largo do Palácio.

\section{CONSIDERAÇÕES FINAIS}

A linha de pesquisa Cultura Material e História possibilita uma abordagem enriquecedora do processo histórico, como pudemos constatar no estudo sobre as modificações no espaço urbano sob a influência do movimento higienista. Através desse viés evidenciamos aspectos importantes que passaram despercebidos na historiografia oficial. Vimos que, apesar de encontrar forte resistência dos moradores e autoridades, o Movimento encabeçado pelos médicos idealista levou à alterações significativas no ordenamento urbano. Neste artigo focalizamos a segregação da Cadeia Pública para fora dos muros da cidade, assim como ocorreu com o cemitério e os hospitais na mesma época.

A pesquisa mostrou que as mudanças na estrutura e nas feições dos Monumento não são fortuitas, manifestam processos históricos em curso. A observação cuidadosa dos mesmos nos informa sobre determinado tempo e relações sociais hegemônicas, mas em constante tensão. O estudo da localização, estrutura e materiais construtivos empregados nos fornecem elementos insuspeitos sobre as transformações ocorridas. Como não se impressionar ao saber que espaços ocupados por séculos por encarcerados se transformaram em escritórios climatizados? Paredes e telhado construídos por indígenas sob condição servil serem, tempos depois, reformados por africanos escravizados, e passado mais um século, revestidas com outros materiais por operários assalariados?

Algumas Construções permanecem ad infinito e os seres humanos, as sociedades (com suas arraigadas crenças, hábitos e costumes) passam por elas. Quanto à Casa de Câmara e Cadeia, pessoas viveram debaixo daquele teto, cumpriram sua pena, depois deram lugar a outras. Poucos vestígios restaram a não ser registros fortuitos. $\mathrm{O}$ Recenseamento da Capital representa um instantâneo dos homens e mulheres que ali 
estavam em 1855. Através dele sabemos que alguns vieram com sua cultura de muito longe, uns de além-mar, outros de terras fronteiriças e distantes, ainda que a maioria tenha nascido por ali mesmo. Todos, por seus atos ou injustiças, tiveram que se submeter a um poder maior e cumprir sua pena. Restou apenas a anotação de seus nomes, da cor de sua pele, de suas idades. Através desses indícios sabemos seu lugar naquela sociedade, se eram jovens, se tinham uma família, se havia interesse em sua liberdade ou não. Mas todos passaram um tempo por entre aquelas paredes, debaixo daquele telhado e se foram, e a Casa permanece no mesmo lugar à espera das futuras gerações.

\section{REFERÊNCIAS}

ÁLBUM, Maranhão Ilustrado: Gaspar Teixeira \& Irmãos, 1899.

ARQUIVO PÚBLICO DO ESTADO DO MARANHÃO. Primeiro Caderno de Recenseamento da Capital. São Luís, 1855.

BIBLIOTECA DIGITAL LUSO-BRASILEIRA E BIBLIOTECA NACIONAL DIGITAL DO BRASIL. Planta da cidade de São Luís, por J. Veiga, 1858. Disponível no site http://bdlb.bn.gov.br/acervo/handle/123456789/272638?locale-attribute=pt_PT

BRAUDEL, Fernand. Civilização material, economia e capitalismo, séculos XVXVIII: as estruturas do cotidiano. São Paulo, Martins fontes, 1995, v. 1.

CUNHA, Gaudêncio. Maranhão 1908. São Luís, Tipogravura Teixeira, 1908.

COE, A. J. H. "NÓS, OS OSSOS QUE AQUI ESTAMOS, PELOS VOSSOS ESPERAMOS": a higiene e o fim dos sepultamentos eclesiásticos em São Luís (18281855). (Mestrado em História Social). Universidade Federal do Ceará. Fortaleza, 2008.

FUNARI, Pedro Paulo. A Arqueologia de Palmares - Sua contribuição para o conhecimento da cultura afro-americana. In. REIS, João José \& GOMES, Flávio dos Santos. Liberdade por um fio. História dos Quilombos no Brasil. ${ }^{a}$ Reimpressão. São Paulo: companhia das Letras, 1996.

Os historiadores e a cultura material (fontes arqueológicas). PINSKI, Carla Bassanezi (org.) Fontes históricas. 3a ed., 1ª reimpressão, São Paulo: Contexto, 2014. 
GERMANO, Nivaldo; RIBEIRO, Elias Nascimento; LOPES, Ludmylla Fontenele. CAIS DA SAGRAÇÃO: O Processo de Modernização da Cidade de São Luís no Século XIX. In: II Simpósio de História do Maranhão Oitocentista: disputas políticas e práticas de poder, 2011, São Luís. ANAIS II Simpósio de História do maranhão Oitocentista, 2011. v. 1.p. 1-13.

HORTA, M. L. P; GRUNBERG, E; MONTEIRO, Q. Guia básico de educação patrimonial. Brasília: IPHAN, Museu Imperial, 1999.

LACROIX, Maria de Lourdes. A fundação francesa de São Luís e seus mitos. 2 ed. São Luís: Lithograf, 2002.

LIMA, Tania Andrade. Arqueologia como ação sociopolítica: o caso do Cais do Valongo, Rio de Janeiro, século XIX. Revista Latino-Americana de Arqueologia Histórica. Vol. 7, No. 1, Jan - Jun, 2013.

MARQUES, César Augusto. Dicionário histórico e geográfico da Província do Maranhão. Rio de Janeiro: Fon-Fon e seleta, 1970.

OLIVEIRA, Antonio Guimarães de. Becos \& Telhados. São Luís, Dakotas Editoras Ltda, 2018.

PACHECO, Conceição de Maria Ribeiro; ALVES, Jossilene Louzeiro. ESTADO SANITÁRIO NA PROVÍNCIA DO MARANHÃO (1850/60) In: II Simpósio de História do Maranhão Oitocentista: disputas políticas e práticas de poder, 2011, São Luís. ANAIS II Simpósio de História do maranhão Oitocentista, 2011. v. 1. p. 1-17.

PESEZ, Jean Marie. História da cultura material. In: Le Goff, Jacques. A História Nova. São Paulo, Martins Fontes, 1998.

REIS, João José. A Morte é uma Festa: ritos fúnebres e revolta popular no Brasil do século XIX. São Paulo: Companhia das Letras, 1991.

ROCHE, Daniel. História das coisas banais: nascimento do consumo nas sociedades do século XVII - XIX. Tradução de Ana Maria Scherer, - Rio de Janeiro: Rocco, 2000.

SÃO LUÍS, ILHA DO MARANHÃO E ALCÂNTARA, Guia de Arquitetura e paisagem = São Luís Island of Maranhão and Alcântara: An architectural and landscape guide - Ed. Bilíngüe. - Sevilha: Consejería de Obras Públicas y Transportes, Dirección General de Arquitectura y Vivienda, 2008.

SILVA FILHO. Olavo Pereira da Silva. Arquitetura Luso-brasileira no Maranhão. $2^{\text {a }}$ ed. Belo Horizonte: Formato, 1998. 
TEIXEIRA Manuel C. A forma da cidade de origem portuguesa. São Paulo: Editora Unesp, 2012.

Recebido em: 01/06/2021

Aprovado em: 25/06/2021

Publicado em: 30/06/2021 